\title{
Noblesse, apps et médecine
}

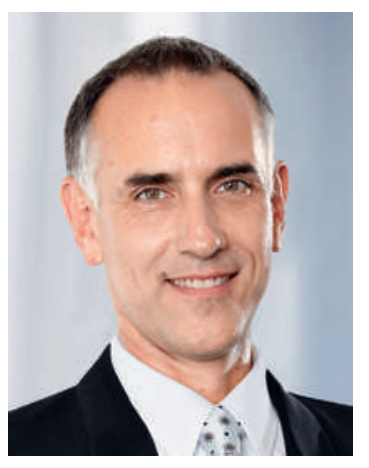

La noblesse évoque histoire, tradition et valeurs; bref une aura qui entoure également la profession de médecin. Mais que signifient histoire, tradition et valeurs à l'heure des technologies modernes et des médias sociaux? Dans un entretien paru dans le bulletin de la noblesse allemande («Deutsches Adelsblatt»), le baron von Hoyningen désigne quatre piliers de la noblesse: attachement aux valeurs, grandeur de l'âme, culture élitaire, attachement à la famille. Au sujet de l'attachement aux valeurs, il précise «vision chrétienne du monde, identification avec sa terre natale et sa patrie ainsi qu'éducation et intelligence du cœur». La grandeur de l'âme s'exprime dans la «courtoisie, loyauté et compétence sociale». La culture élitaire se manifeste «extérieurement par un mode de vie raffiné, des demeures et un mobilier nobles, de belles orfèvreries, de la porcelaine et de l'argenterie de qualité.» C'est sans commentaire que je laisserai au lecteur le soin d'imaginer le regard du baron sur les valeurs familiales.

\section{L'individualité parfois fragile du patient doit orienter l'acte médical, et non des notions de rendement.}

Qui n'a pas de sang bleu peut aujourd'hui entrer par alliance dans une illustre lignée - c'est déjà monnaie courante dans la haute noblesse: sic transit gloria mundi, ainsi passe la gloire du monde. Les réseaux sociaux, Facebook ou Myspace en tête, les blogs, les dialogues en ligne ou les services de microblogage comme Twitter ne s'arrêtent pas aux portes des châteaux. Tout comme YouTube, Instagram \& Co. ont déjà pénétré les professions de la santé. Ainsi médecins, ducs ou barons pianotent comme tout un chacun sur leurs applications plus ou moins attachées aux valeurs de ce monde, et se retrouvent sur Facebook. D'autres, qu'ils soient chevaliers ou fraîchement élevés au rang de médecin après un master, affichent leurs news sur Twitter.

Au premier coup d'œil, les nouveaux modes de communication, aussi stimulants et passionnants soient-ils, sont difficilement compatibles avec les traditions et les valeurs du corps médical, fruits de l'héritage initialement légué par Asclépios, le père mythologique de la médecine, et transporté par tous les médecins qui nous ont précédés. Soigner et aider restent au cour de notre vocation, primum nil nocere, compétence professionnelle, compassion et secret médical sont nos vertus fondamentales. Nous jouissons encore d'un prestige social élevé auprès de la population. C'est pourquoi l'individualité parfois fragile du patient doit orienter l'acte médical,

\section{Les nouveaux médias auront \\ toute leur place aux côtés des valeurs traditionnelles.}

et non des notions de rendement. Pour nous, c'est notre identité de médecin qui devrait toujours primer, et non l'économie et encore moins la technologie. Pourtant, nous n'aurons pas le choix, nous devrons trouver un modus operandi pour composer avec les directives économiques ou justement avec les possibilités infinies des nouvelles technologies (de la communication). Les réseaux sociaux s'amplifient par résonnance réciproque, ils exercent une influence accrue sur notre vie privée et notre travail. Cela a motivé les organisations professionnelles et les commissions d'éthique à repenser les fondements déontologiques à l'heure du numérique: il ne s'agit pas de réinventer l'éthique mais de la spécifier.

Il est souhaitable de transmettre les principes fondateurs de notre profession sans les aliéner. Les jeunes générations de médecins nous montreront que les nouveaux médias ont toute leur place aux côtés des valeurs traditionnelles - qui, pour nous, s'appellent respect, tolérance, empathie et identification professionnelle. Même si les nouveaux supports de communication constituent un formidable moteur pour optimiser le travail, plus interagir, et faire vivre la démocratie directe, espérons que les jeunes médecins contribueront aussi à recentrer l'attention sur les véritables enjeux, à savoir soigner les personnes le mieux possible en tenant compte des progrès de la médecine et de l'évolution démographique de la population. Si noblesse oblige, être médecin oblige à coup sûr aussi!

Dr Gert Printzen, membre du Comité central de la FMH, responsable du département eHealth - informatique et documentation médicales 